\title{
FUTURE INNOVATIVE CONSTRUCTION TECHNOLOGIES: DIRECTIONS AND STRATEGIES TO INNOVATE CONSTRUCTION INDUSTRY
}

\author{
YUSUKE YAMAZAKI \\ General Manager, Division of Marketing \& Planning, \\ Technology Planning Office, SHIMIZU CORPORATION, \\ Seavans South, No. 2-3, Shibaura 1-chome, Minato-ku Tokyo 105-8007, JAPAN \\ yusuke.yamazaki@shimz.co.jp
}

\begin{abstract}
:
The paper aims to discuss future direction of management of innovative technologies toward construction innovation. Our focus here is technology and knowledge fusions. At first technology and knowledge fusions in building construction are described. Secondary processes of technology and knowledge fusions are analyzed focusing on automation technology and information technology. Thirdly, a strategy to innovate construction industry is proposed from a viewpoint of technology and knowledge fusions. Finally, future directions and strategies of technology and knowledge fusions to develop future innovative construction technologies are to be presented.
\end{abstract}

Keywords: innovation construction fusion technology knowledge automation information management strategy

\section{INTRODUCTION}

The form of the building construction is different from the manufacturing industry, due to problems such as low productivity, many construction waste and materials, worker's accidents that are caused by the labor intensive works performed in job-site under built-to-order production supported by various typed of project participants.

To solve the problems, advanced technologies have been introduced from manufacturing industry with their concepts and methods to improve quality and productivity such as industrialization, prefabrication modularization, mechanization, automation and computerization.

Various types of advanced construction systems have been researched, developed and implemented in specific building projects to try to solve the problem of the low productivity by introducing advanced technologies such as prefabrication, automation and information technologies from manufacturing industry as well as concepts and methodologies associated with new technologies. The construction systems aimed to change styles of building construction to that of factory production through sophistications of developed technologies, methodologies and concepts.

Essentially construction firms present their engineering and management services at project level, appropriate approaches to innovate projectbased firms based on efficient methodologies and clear strategies to perform technology developments are relevant. Our focus here is technology and knowledge fusions.

Technology fusion is an emerging methodology to integrate potential technologies among different disciplines, and it is also viewed as an effective approach to assisting construction firms respond to the difficult environment in which they are operating currently.

Knowledge fusion is also an emerging methodology to improve organizational knowledge creation ability that has been introduced to construction industry as by dynamically transform implicit knowledge and explicit knowledge of an organization.

To promote technology fusion, it is essential to have a structured way with clear goal, concept and strategy. Formerly Computer Integrated Construction (CIC) was regarded as a strategy to promote technology and knowledge fusions. CIC is an adaptation of Computer Integrated Manufacturing (CIM) to construction industry, and it is also viewed as an effective knowledge fusion driver, because manufacturing industry intended to innovate not only their production system but also their organizational knowledge management system by introducing CIM concept. To demonstrate the concept of CIC in construction industry, prototype systems were implemented to promote innovations in its process, organization and product through systematic technology development.

SMART system (Shimizu Manufacturing system by Advanced Robotics Technology) is a part of Shimizu's CIC strategy for developing an automated construction system, which automates a wide range of construction process of high-rise building by 


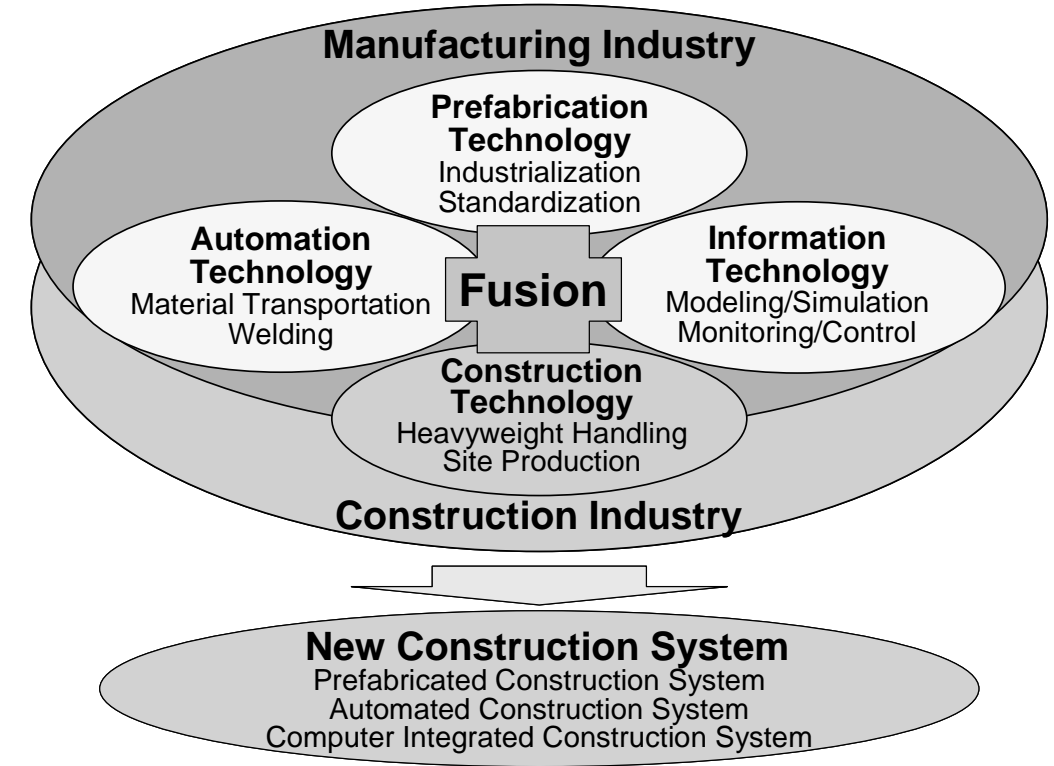

Figure 1. A Conceptual View of Technology and Knowledge Fusion for Construction Industry

integrating prefabrication, automation, and information technologies with construction technology. Also information management systems associated with an automated construction integrate a wide range of design, engineering, planning and management knowledge of the project functions.

By introducing SMART system, amount of labor required and the construction period are both reduced significantly, and the planning and management productivity is increased. However the originally developed SMART system is not applied since two construction projects at early development stage had been completed, the system have been improved and modified to several types of construction systems that are vital at present. Because technology development environment has been changed to focus more effective technology and knowledge fusions with other companies and industries.

Current challenging technology and knowledge fusions are mainly brought by comprehensive applications of IT systems. Major IT systems introduced to construction projects are well depend on 3D-CAD systems and networked communication systems, which is effectively applied to product design, production planning, real-time monitoring of construction process, control of transportation equipment in execution stage, and management of procurement and executions. By utilizing those IT systems, a remarkable progress has been made in the field of integrated management of process, organization and product of the project.

Future construction innovations will also depend on technology and knowledge fusions among different companies and industries. To promote technology and knowledge fusions, systematic and organizational promotion of technology development to be adaptable to needs and technologies for greater sophistication and diversity in construction projects are relevant. Also continuous implementations of prototype systems in actual construction projects to show the clear goals and concept. The implementation requires clear strategy promoted as a policy of construction industry, which aims to create new production systems associated with new business systems by introducing innovative material technologies and environmental preservation technologies.

\section{TECHNOLOGY FUSION IN BUILDING CONSTRUCTION}

Technology fusion is an emerging methodology proposed by Dr. Kodama. By fusing technologies, companies can create new products, markets, and industries, and remain ahead of their competitors. Technology fusion blends several previously separate fields of existing technology. Three fundamental principles can help companies implement a fusion strategy. First, let the market drive R\&D, not the other way around, through a process called "demand articulation." Second, develop a strong intelligence gathering capability both as a defense mechanism against competitors and as a source of new ideas. Third, and most important, take part in cross-industry R\&D projects [2].

Reviewing the past technology development process in Japanese construction industry, advanced technologies have been introduced to improve construction efficiency as a fusion of prefabrication, information, automation and construction technology. In the end of 1960's, large construction companies started to develop super high-rise building systems and industrialized building systems reflecting economic boom and deregulation. Major technologies, which enabled super high-rise building systems, were high-stress steel, high-performance tower crane, and lightweight curtain -wall and computer-supported structural analysis developed by manufacturing companies. Those technologies were 


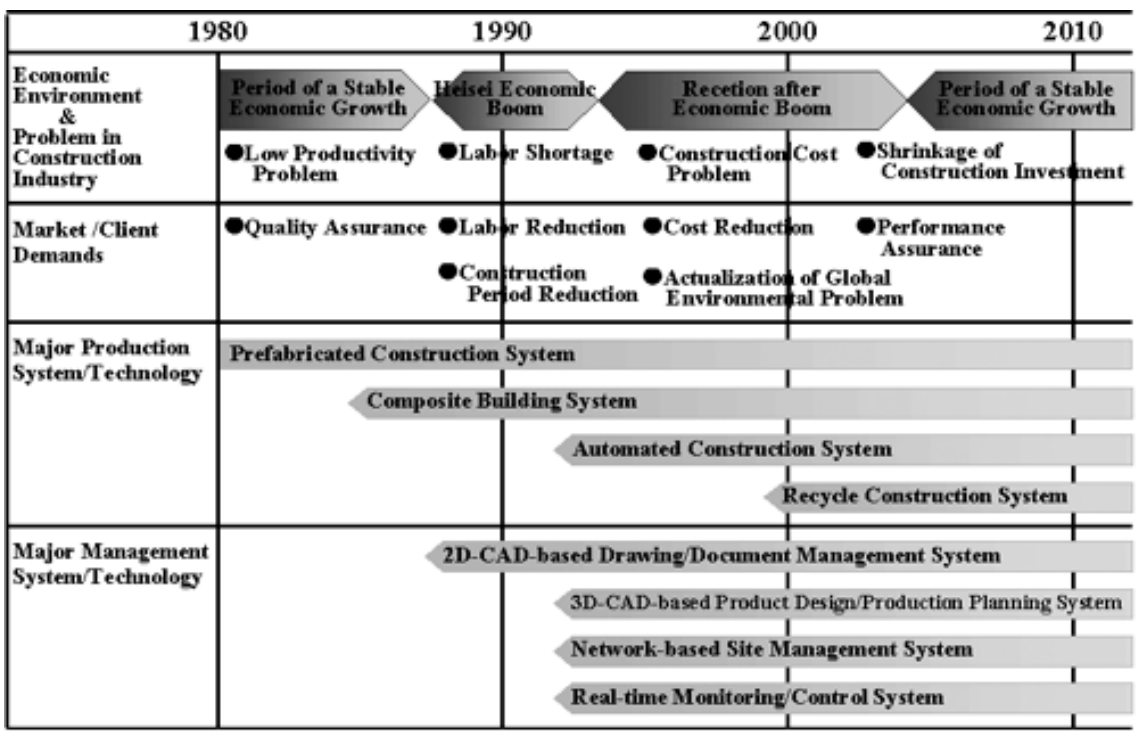

Figure 2. Process of Construction Technology Development in Japanese Construction Firms

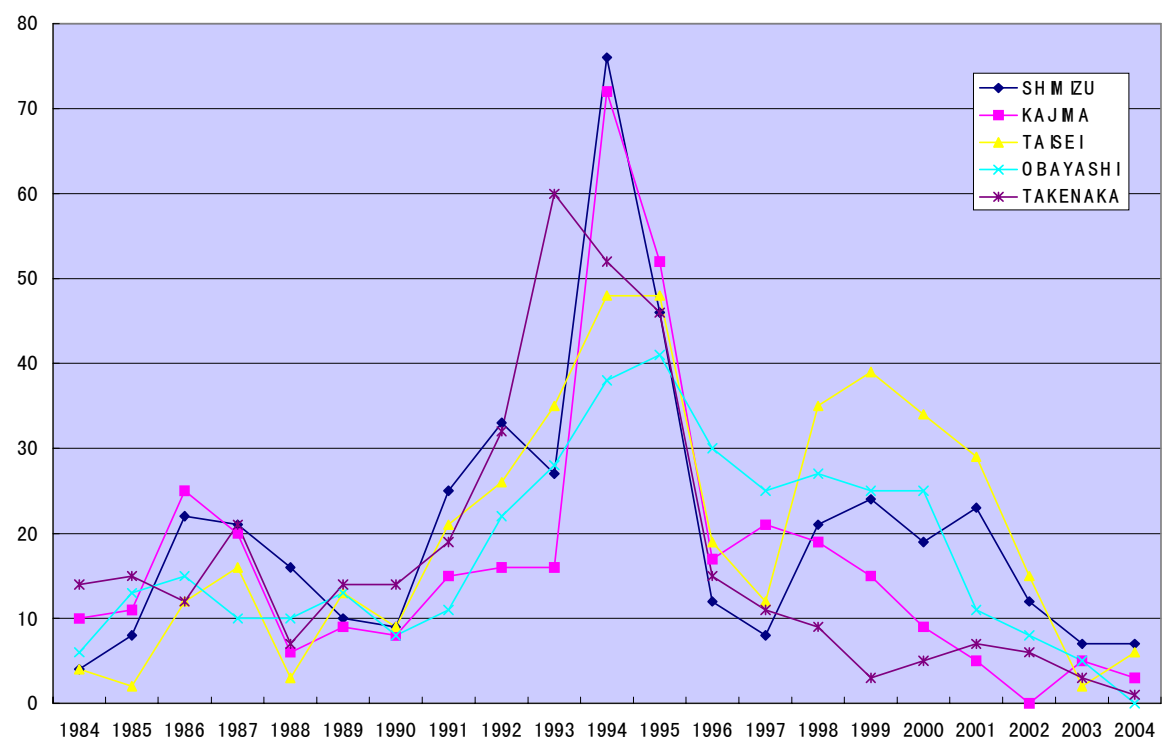

Higure.3 Changes in the Numbers of ratent Applications in the rield of

Construction Automation by Top Five General Contractors in Japan

sophisticated and integrated with construction technologies, resulting in innovative building and construction systems. Also prefabrication technologies were introduced to develop industrialized building systems, which mainly applied to standardized condominiums. Not only construction companies promoted the developments but also manufacturing companies, electricity companies and chemical companies started the development to establish new business markets. The prefabrication technologies were also integrated with construction technologies, resulting in various types of standardized production systems with quality control techniques.

In the middle of 1980's, many large construction firms have started huge amount of investment to adapt innovative automation and information technologies to building construction based on increasing construction market. At first, many of the efforts were being carried forth in the context of the Computer Integrated Construction (CIC). To implement CIC, a systematic approach for applying computerization and automation to building construction by illustrating future vision of building construction was introduced.

The visions are represented as conceptual models to develop CIC by carefully investigating the functional distributions among design, engineering, planning, procurement, construction and required processes. For example, Shimizu's model was divided into four major functions: (1) Integrated design/construction planning system, (2) factory automation system, (3) site automation system, and (4) Multi-project management system with central project database. These conceptual models described strategies to exploit innovative technologies among improved functions. 


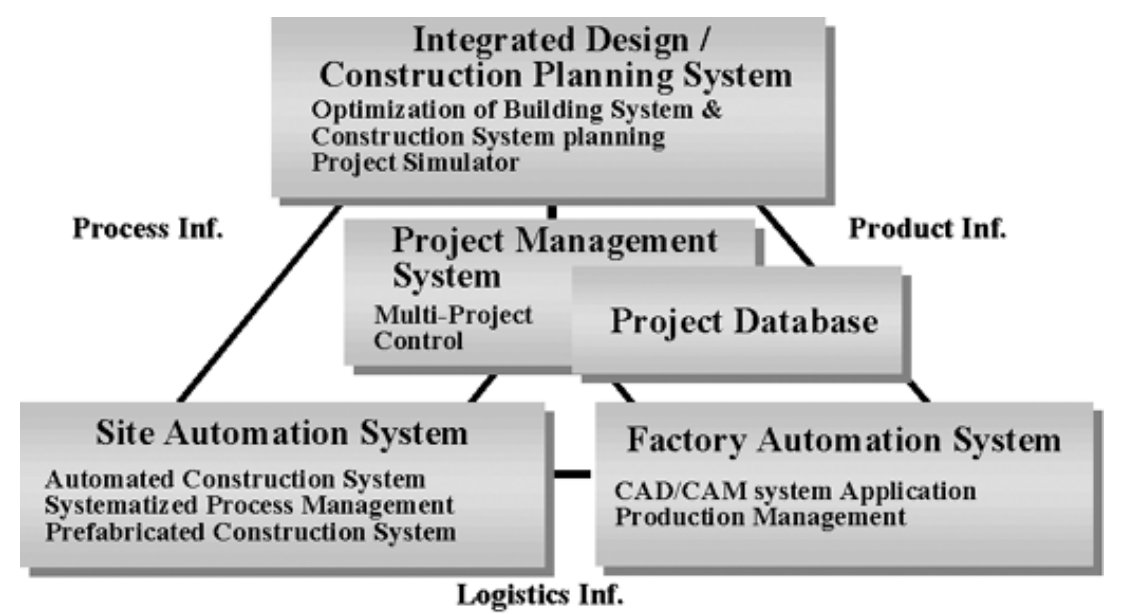

Figure 4. Conceptual View of Computer Integrated Construction

Applications of automation technology to building construction had been started as development of construction robots, which aimed to resolve some of the difficulties associated with construction activities. Since the robots were developed as single-task oriented robots, they could not remarkably improve efficiency of whole construction processes and activities, because they can only improve a part of construction processes and activities. To attain highly improved construction process, automated construction systems were researched and developed. The systems were illustrated as all weather automated construction systems that aimed to eliminate the bad image of construction industry, to create better working environment like factory and to improve quality of the products by utilizing automation and prefabrication technologies.

Shimizu's automated construction system is named SMART system, which automates a wide range of construction procedures, including: the erection and welding of steel frames; the placement of pre-cast concrete floor planks, exterior and interior wall panels; and installation of various units. The system utilizes prefabricated components extensively including columns, beams, floorings and walls, and the assembly of these components is simplified by the use of specially designed joints. In addition, this assembly process is orchestrated by real-time computer control, resulting in construction site operation in a highly automated way. The heart of the SMART system is composed of the lifting mechanisms and automatic conveying equipment installed on the operating platform, which is ultimately to be the top roof of the building. Steelframe columns, beams, floorings and walls are automatically conveyed to designated locations, where they are effectively assembled and mounted with specially made joints. The steel-frame welding process is also automated with the invention of an automatic welding machine. When one of the floors of building is completed, the entire automated system is lifted vertically and the work for next floor commences immediately. Thus construction work proceeds systematically, floor by floor, until the whole building is completed. The SMART system also provides complete all-weather enclosure for site, accommodating satisfactory working conditions and safety, and leading to higher quality and durability for the product.

Reviewing labor productivity which is almost equal to efficiency of construction site work, labor productivity has been declined since 1990, however that of whole industry, especially labor productivity of manufacturing industry has been expanding, that means R\&D investment has not effectively contributed to increase value of construction industry relatively compared with manufacturing industry.

Current challenging technology fusions are brought by comprehensive applications of IT systems. Since the middle of 1990's, Japanese construction industry has been involved in a severe recession. Construction companies had to improve their performance more and more by introducing information technology at whole business processes, functions and organizations due to the rapid changes in construction market. The technology fusions are well depend on 3D-CAD system, which is effectively applied to product design, production planning, realtime monitoring of construction process, control of transportation equipment in execution stage, and web-based communication system for site management. By utilizing those IT systems, a remarkable progress has been made in the field of integrated management of process, organization and product. Also the applications promoted knowledge fusions as well as technology fusions.

Recent needs for global environment preservation is making another technology fusion that is concrete recycle system. However prefabrication is useful to reduce construction waste, recycling of concrete waste produced by demolition is critical in present construction industry. To solve the problem, construction system associated with closed-loop concrete recycle system has been developed by introducing inverse manufacturing technology. Thus technology fusion is regarded as a key issue to innovate construction technologies. 


\section{KNOWLEDGE FUSION IN BUILDING CONSTRUCTION}

In contrast with technology fusion, knowledge fusion has been introduced to construction industry as activities of organizational knowledge creation. In manufacturing industry, the series of researches with regard to organizational knowledge creation have been performed by Nonaka [4]. Our research started from the application of the framework presented by Nonaka to building construction. The integrated organizational knowledge creation model illustrated by Nonaka presents dynamic interactions as four types of activities: socialization, externalization, combination and internalization.

When the concept is applied to building construction, the transmission of expert skills and implicit knowledge through actual jobs from a skilled engineer to an unskilled engineer is socialization. Documentation and standardization of personal or group know-how is externalization. Systematization of documented knowledge in design, engineering, planning and management by computer programs is combination. Knowledge acquisition through development of new technology based on already possessed technologies is internalization.

Our focus here is on internalization and externalization, which are caused by interactions between implicit knowledge and explicit knowledge. Since the organizational knowledge creation does not limit to take one-way exploration starting from person level, a creative organization should have a system or a structure, which can explore linkages between four modes of knowledge creation.

In construction industry, researches on constructability presented similar results. The research pointed out the need for increasing understanding of the type of knowledge involved in experiences from engineering and construction projects. Constructability improvement is recognized as the evolution of four interaction modes of knowledge creation based on opportunities to better capture and transfer experiences and knowledge between design and construction. Since constructability researches took analytical and formulated approaches, the utilization of exogenous source of knowledge and combination of formalized knowledge are relevant.

Consequently, emphasis has been put on documentation and computer utilization to establish database and knowledge base with constructability. The activities are viewed as combination and externalization. Reflecting these researches, our focus is put on the dynamism of organizational knowledge creation, especially effective mechanisms to be adapted to project-based companies

Usually, the knowledge used in design and construction is divided into two types: (1) Implicit knowledge such as evaluation and application of building systems and construction systems, which are acquired through experience and are possessed by individual designer and planner; and (2) Explicit knowledge such as composition and functions of building systems and construction systems, which are shared as technical standards among groups, departments and organizations and are usually stored in the form of documents.

Reviewing successfully applied construction technologies, design, engineering, planning and management knowledge associated with the developed technologies are recognized as implicit knowledge at the beginning of development. According to the exploration of development, such knowledge is transformed into explicit knowledge such as technical standards of application procedures in the form of documents. The explicit knowledge is applied to actual building projects, and then the technologies require further improvement and sophistication to be more useful ones, such as hybrid building systems, automated construction systems and advanced computer applications. These developments need integrations and interactions among different types of knowledge in various disciplines.

Consequently, new implicit knowledge in design, engineering and construction is created through the integrated and interactive investigation by development organizations. Thus organizational

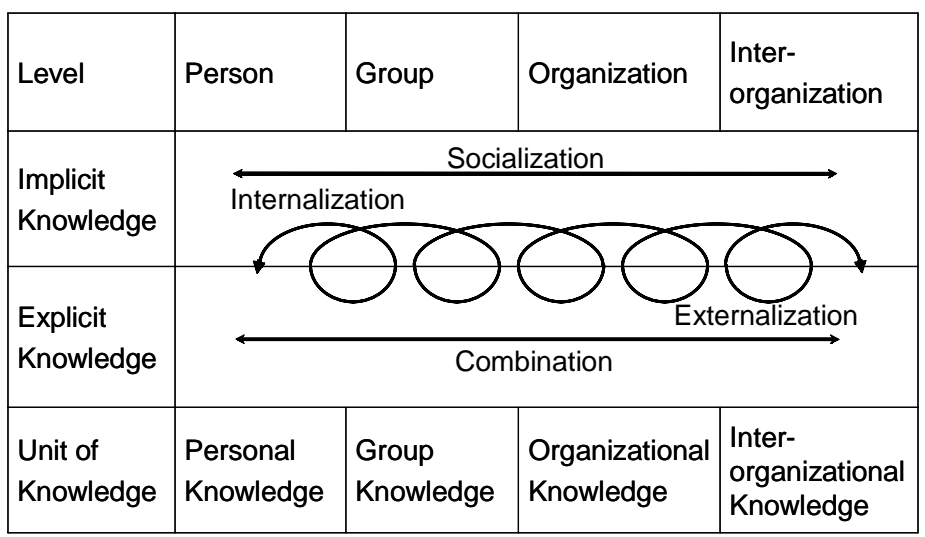

Figure 4. Evolution of Organizational Knowledge Creation 
knowledge creation is performed as dynamic circulation and interaction among implicit knowledge and explicit knowledge through different levels of development stages. On the other hand, we see poor knowledge creation in many cases. Many technologies become out dated due to the lack of organizational knowledge creation.

One reason why the impact of the organizational knowledge creation approach on construction companies will be crucial is that it supports high level coordination between human and computer. The second strength of this approach is that it will provide the well-organized environment for transmission of information and knowledge, as the prerequisite for the use of an object-oriented approach in the integration of information and knowledge. This will remove current poorly coordinated transfers of information and knowledge between the various organizations. The environment will also provide more flexible decision making process among all critical design and planning functions. Thus organizational knowledge creation in building construction should be promoted to innovate construction industry.

\section{CONSTRUCTION INNOVATION BY TECHNOLOGY AND KNOWLEDGE FUSION}

To investigate the future strategy to innovate construction industry, it is important to introduce a structured way. Originally technology and knowledge fusions support a high level of coordination among process, organization and product. The systemic approach will provide a welldefined environment for the effective strategy for exploitation of the information technology to promote technology and knowledge fusions.

\subsection{Management of technology by an integrated production system}

Management of technology is defined as reorganization of potential construction technologies to efficiently resolve some of the difficulties associated with market demands for low cost and high standard and with increasing competition. Since construction technologies have been developed and stocked as individual or elemental technology to solve specific problems in general. However they are efficient as technology itself, inappropriate combinations of those technologies introduced by individual and insufficient investigations often cause contradictions and complexities in construction stages, resulting in losses of time and expense. Therefore organizationally integrated subsystems to simulate and define an optimal construction system as a best mixture of enable technologies are relevant.

In CIC concept, the construction system has been illustrated as a site automation system known as SMART system. The system is a portion of strategy for construction innovation that covers construction technologies for super high-rise buildings including automated transportation system of prefabricated components, jacking-up systems of operating platform and real-time monitoring of simultaneous production processes with various machines.

However higher sophistication of an automated construction system is implemented, economical changes in construction market forces the technology to be modified either to reduce automation level of the construction system or to seek an alternative construction system based on other concept. The former approach is to restrict applications of automation areas to adjustment of transportation machines that are difficult in manual control The later approach is to focus on material transportation system
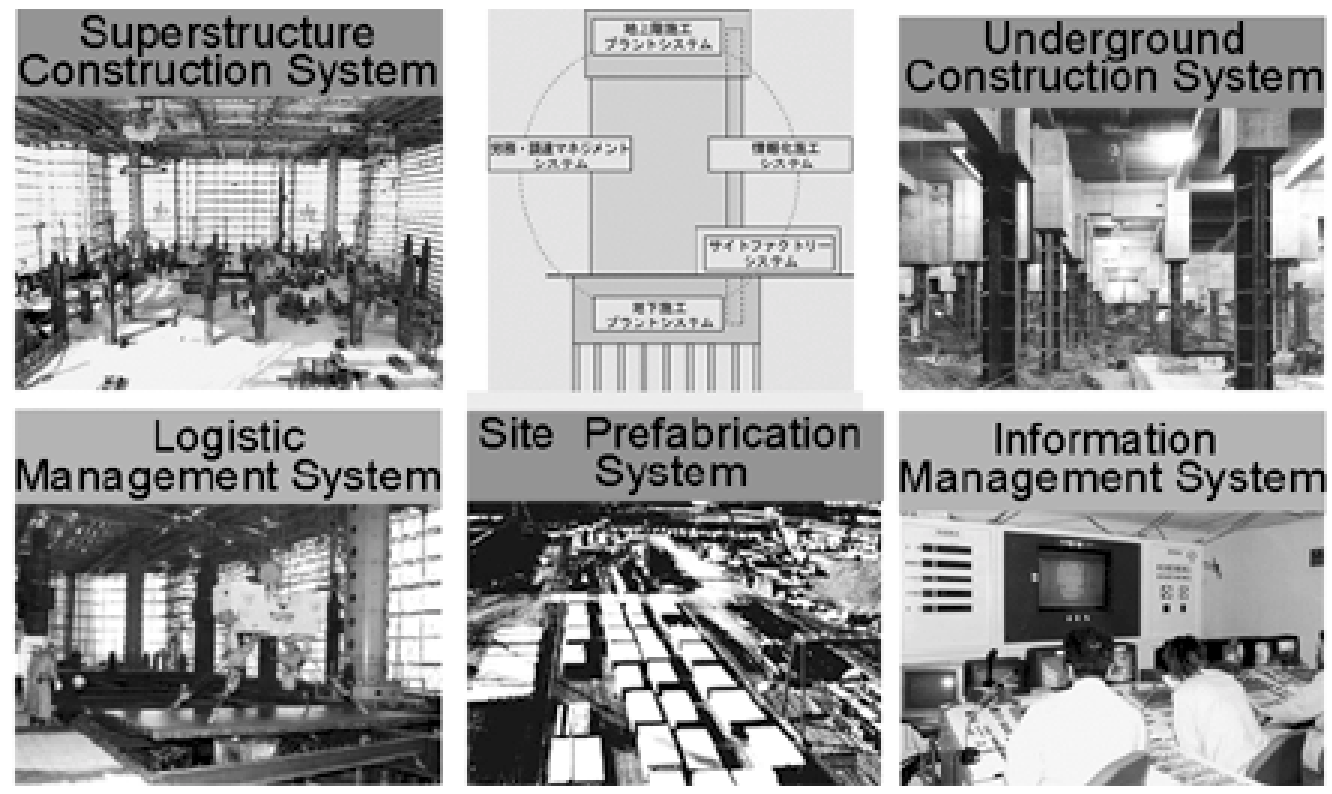

Figure 5. Conceptual Composition of An Integrated Production System 
and its control system by intensive utilization of network, database, monitoring and control systems. A systemic strategy is currently undertaken to explore and to combine the both restructuring and alternative approaches to be a new paradigm of physical construction system from a viewpoint of technology management.

Integrating engineering hardware and management software composes the physical model of proposed construction system. The hardware system is consists of three physical engineering subsystems: Construction plant system for superstructure to systematically incorporate transportation and assemly of prefabricated components and units with minimized temporal facilities and, (2) Construction plant system for substructure to widely introduce mechatoronics technology under simultenuos construction of superstructure and substructure, and (3) Site plant system to assemble components and to supply as units for construction plants.

The software system organizes two complemental management systems: (1) Logistic management system that covers package planning and procurment of materials and labors, and (2) Production information management system that incorporates the functions of analysis, simulation, monitoring and contorol with three plant systems.

Among those subsystems, production information management system is an integral part of the proposed construction system to adopt optimum information technology based on characteristics of construction plants to improve engineering efficiency as a total sysytem. Another function of production information management sysytem is to improve management efficiency by sharing production information with quality, cost, deivery, safety and environmental effects among participants of the project via project database and network systems. Thus strategy in management of technology is set up to integrate construction technology and information technology by subdivision and restructuring of physical construction systems from a viewpoint of production information management.

\subsection{Management of product and process by concurrent and collaborative environment}

The decision-making problems in a construction project often caused by precise subdivision of project processes and functions due to complexities and varieties in current construction projects. Consequently ineffective integrations of information, knowledge and technology are found especially in early project stages. The process-to-process and function-to-function information transmissions make decision-making processes more complicated, which are recognized not only in internal project processes but also in external project processes with participants of clients, design/engineering firms, constructors and suppliers.

In case of large-scale construction projects, a lot of time is spent to exchange information among project participants through value engineering, constructability investigation based on incomplete detail design, and coordination with design documents and construction drawings. Consequently early introductions of construction knowledge and information in a form of concurrent design and construction planning function is important

To realize the function, two types of process integration are required: (1) Horizontal integration in a project organization as a collaborative work environment among designers, engineers and managers through optimal combinations of enable construction technology and information technology, and (2) Vertical integration in project processes as a

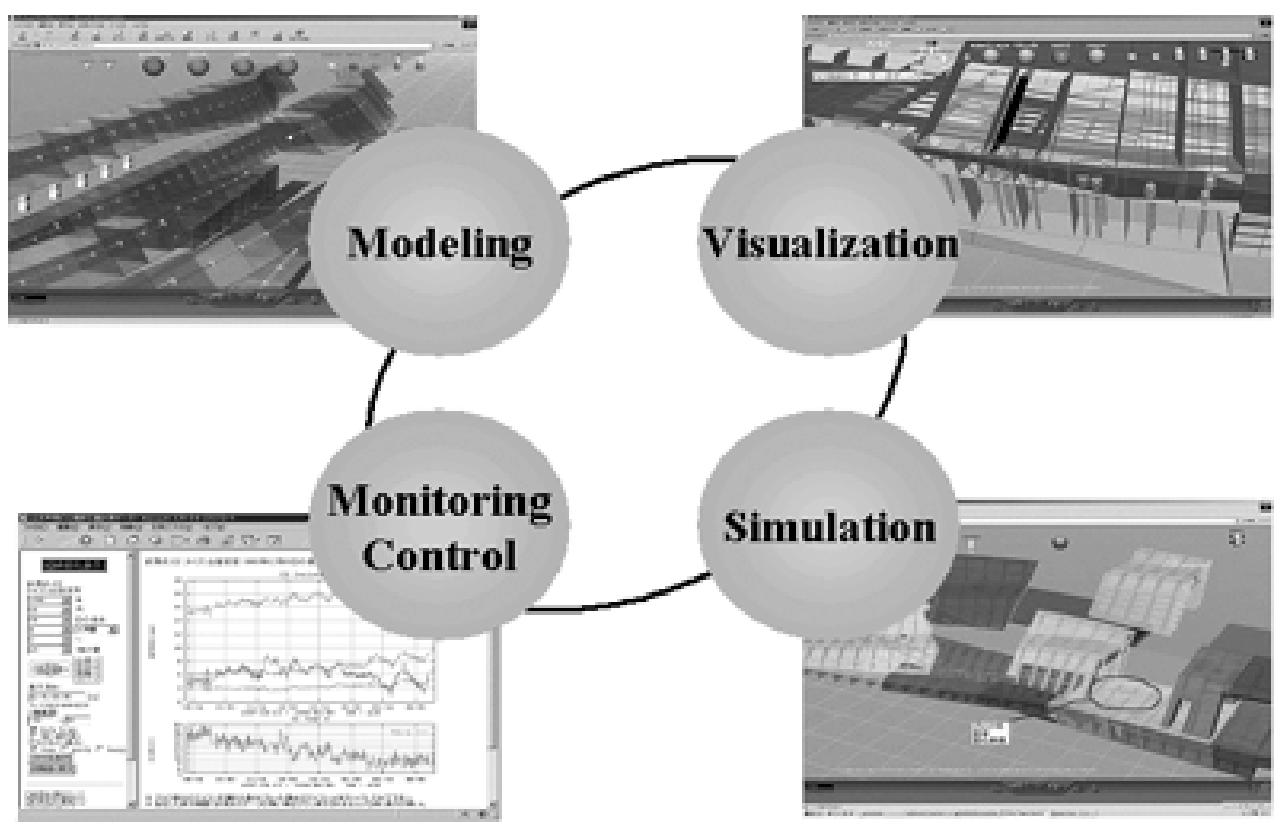

Figure 6. Functional View of 3D-CAD Based Production Information Management 
concurrent work system among designers, engineers, constructors, fabricators and suppliers. The collaborative work environment in practice should be established as product design system by integrated design and construction drawing using CAD and EDI technologies.

The concurrent engineering environment for construction simulation should be established under production planning system using 3D-CAD systems with formalized building/construction information models by which various simulation systems are interactively utilized. The 3D-CAD applications should also be carefully investigated by considering efforts in data input and benefits by repetitive use of data. Currently product design and production planning are key issues towards total product and process innovation, and most of efforts should be undertaken in this direction with standardization of product and process models.

\subsection{Management of organization by IT- based knowledge management system}

Recent innovation in business process reengineering has provided an effective methodology to organizationally acquire, utilize and create useful knowledge associated with design, planning and management of construction projects. Originally IT applications to different levels of organization contain standardization of work flows and externalization of implicit knowledge to be utilized as well-organized processes and explicit knowledge to improve total efficiency of the project processes

Current IT-based applications to share information and knowledge among individuals, groups and organizations in construction projects are divided into four major functions: (1) Internet-based realtime monitoring systems to share measured data with structual performance, and transportation information of building materials among site engineers and supporting engineers in headquarters, branch office and institute of technology; (2) Webbased information management system to share information with construction progress, pending issues, and visual information of construction site, among clients, designers, engineers, constructors, fabricators and suppliers; (3) Total project management system among different project blocks at site, and (4) Knowledge management system among same type of building projects such as highrise condominium, hospitals and semiconductor factories that require specific engineering knowledge and technical information.

Since management of organization aims to integrate project functions to realize the customer satisfaction with a construction project including quality assuranc e and performance assurance under requirements and constraints, optimal combination of design, engineeri ng, procurement, construction and maintenance syste ms by organizational knowledge management are nec essary. Therefore, lifecycle management of informati on throughout feasibility study to maintenance and re novation should also be highlighted.

\subsection{Management of Building Resiurces by Reuse amd recycle Systems}

Companies of in various fields have been raising emphasis on environmental programs. In the construction industry as well, companies are taking steps to reduce their impact on the environment. In Japan, new scheme has been created by the amendment of the low for production to effectively utilize recyclable resources. The promotion in construction industry is performed as $3 \mathrm{R}$ (reduce, reuse, and recycle) activity. Two types of approaches have been undertaken to pursuit zero emission from a viewpoint of technology. One is an improved approach to pursuit for zero emission thorough development and applications of efficient construction technologies to realize the $4 \mathrm{R}$ (refuse, reduce, reuse, and recycle) program at project level. Another is an innovative and challenging approach thorough development of relevant material recycle systems at company level, by introducing innovative technologies such as biotechnology. We believe both approaches are necessary to relentlessly pursuit for zero emission in construction, by promoting the $4 \mathrm{R}$ program at project level.

On the other hand, major innovative approach is posed on recycling of construction by-product. The major resource to be recycled in construction industry is concrete, which occupy about $40 \%$ of total materials used in whole Japanese industry. Amount of concrete waste estimated will exceed the demand capacity of road sub-base in near future, and capacity of disposal facility will not be able to accept concrete waste.

To solve the problem, closed-loop concrete recycle system has been developed by introducing manufacturing technology. A heating and rubbing plant is settled to a construction site to reduce transportation of concrete waste caused by demolition of existing building. Using the plant, huge amount of decomposed concrete is divided to coarse aggregates, fine aggregates and pulverized materials that are recycled as recycled concrete and soil improved materials for the construction project.The other innovative approach is illustrated as development and application of innovative structural materials. Innovative structural materials include super high-strength concrete, super high-tension steel, ultra fine-grained steel so called ultra steel, and innovative composite materials represented by carbon fiber reinforced plastics. These innovative structural materials have feature of not only highstrength as twice as ordinal concrete and steel, but high durability as twice as ordinal concrete and steel, high rigidity and high corrosion resistance. Thus innovative structures using innovative structural 
materials make their lifetime longer and reduce amount of materials by developing non-welding joint between building components which allow them to be reused. The buildings designed by innovative structural systems can be viewed as sustainable buildings. Our target is to develop innovative structural system using innovative structural materials and also to develop structural health monitoring and self-repairing technologies which are to be required in realizing sustainable buildings.

In early 1980's, Shimizu had started a technology development project to seek new structural materials toward 21st century which substitute steel products and rebar. As a result, over 200 new ideas with new materials were identified including super highstrength concrete, fiber reinforced plastics and carbon fiber reinforced plastics. Also several types of innovative structural syatems and buildings were researched to adopt such new materials.

Among such structural syatems, space truss structure system was at first focused, because it has a simple structural system which can also make use of the feature of light-weight easily. The structure divides an external force into only axial forces of members. Secondary a mixed application of super high-strength concrete and ultra steel is set up for a triple skeleton structure system.Triple skeleton structure system consists of three levels of skeletons according to renewal cycle time. The first skeleton is composed of seismic isolation system and high rigged core to be used for 100 to 200 years. The second skeleton is built by ordinal steel structure system with recycleoriented connecting mechanism such as ring-panel non-welding method to be reused every 50 years. The third skeleton is the most flexible skeleton by light steel structure system to be reused every 25 years. Thus the triple skeleton structure system is regarded as a sustainable building system with innovative materials.

With the development of such innovative structure systems, mechanisms to secure structural health are also to be developed. Actually the needs for a structural health monitoring system for civil and building structures are emerging recently. This figure illustrates an image of structural health monitoring system.

The system intensively utilize sensors which are installed in civil and building structures. When earthquake or typhoon make stresses in building, sensor system installed in a building detects failures, defects and cracks and reports information to a data center. The information is also transferred to designer, constructor and owner of the building to acknowledge damages without manual inspections.

A structural health monitoring system using FBGbased optical sensors is installed in a 12-story steel building. The building is equipped with several panel dampers made of low-yielding steel panels. The panel dampers work as energy sinks to reduce the vibration response of the building when subject to a larger earthquake. The structural health monitoring system is hence installed to ensure the structural integrity by monitoring the response of the building. FBG-based optical sensors employed for the system were newly developed to measure strain, displacement and temperature. The installed system was verified to function properly when careful tuning of the system was made.

In Japan, nanotechnology and material research-anddevelopment project team was installed in the bottom of the Council for Science and Technology, and the Ministry of Public Management, Home Affairs, Posts and Telecommunications, the Ministry of Economy, Trade and Industry, the Ministry of Education, Culture, Sports, Science and Technology, and the Ministry of Land, Infrastructure and Transport are
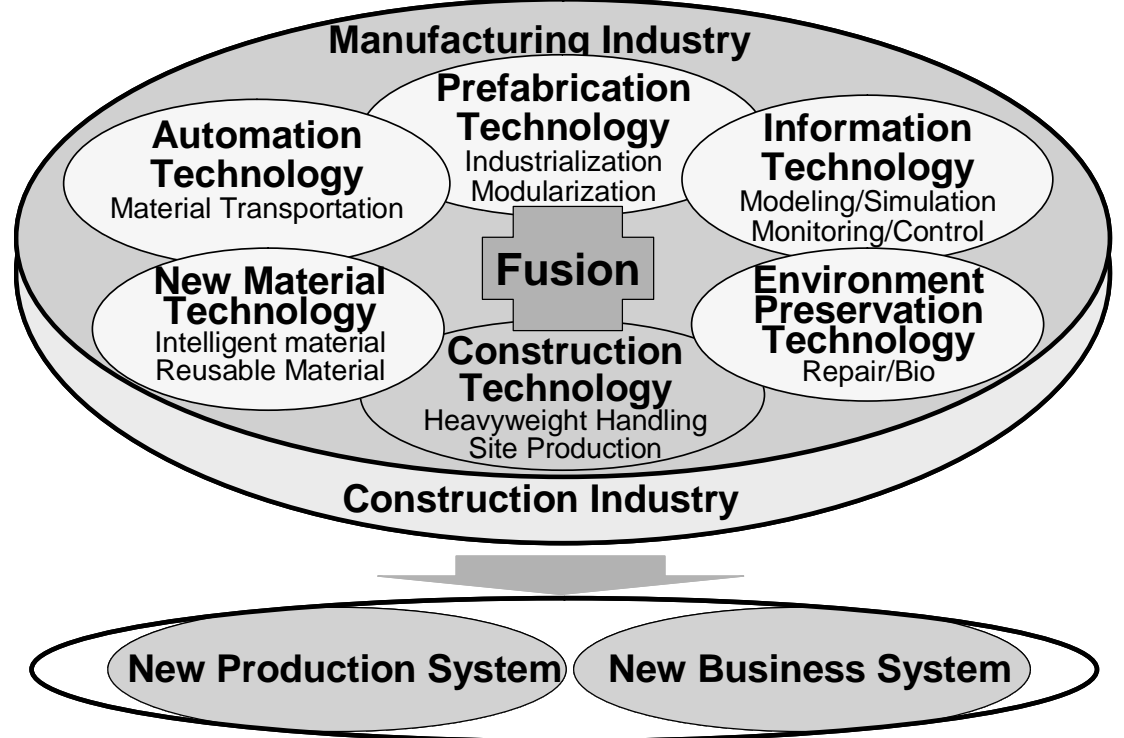

Figure 7. Future Directions of Construction Technologies 
cooperating and promoting under initiative of Cabinet Office. Innovative structure material was taken up as one of the cooperation project, in which not only research and development are promoted through coalition among offices and ministries, but environmental consideration of demonstration in model projects, standardization as JIS, and collaborative support for commercialization and industrialization of innovative structural materials are to be undertaken.

The project schedule is settled for 5 to 7 years, including Research and development of a material utilizable over a short period of time, research and development of a new connection part, research and development of material, connection, design and construction method, research and development of a material utilizable over a long period of time, and structural health check and monitoring. Also the experiment in an actual proof models are planned for buildings and bridges. Innovative materials and methods will reduce the time and cost of construction and greatly extend facility performance, functionality, aesthetics, affordability, sustainability, and responsiveness to changing business demands.

Reviewing past development of innovative technologies, new building systems and structural systems have been realized by development and utilization of innovative structural materials such as high strength steel, high-strength concrete and carbon fiber reinforced plastics. Furure automation technologies and inforamtion technologies will also well depend on the development of new structural sysytems by innovative materials.

\section{CONCLUSION}

For future construction industry, technology and knowledge fusions are key methodologies. To promote technology and knowledge fusions, information technology should be viewed as key technology for project-based construction firms. Introduction of advanced IT systems are well depend on the levels of fusions among information technology and construction technology. Also efficiency of IT systems depends on the clear definition of engineering and management functions of the project. Among such applications, communication systems based on Intranet using webgroupware for project management are widely utilized to share information and knowledge that imply future directions of IT-based knowledge management methodology.

To introduce effective IT systems to project level innovations, IT strategy should be carefully investigated from systemic viewpoint to utilize concurrent and collaborative environment for product and process management, an integrated production system for production technology management and organizational knowledge management system for organization management.
Also technology and knowledge fusions require implementation of prototype systems continuously to be adapted advanced technologies to actual construction projects such as development of SMART system, maintenance of clear strategy promoted by top management such as computer integrated construction, and fusions of new production systems and new business systems toward a industry fusion.

National development program of innovative technologies with a dream needs to be created for economic revitalization. Technology innovation and economic revitalization through active promotion of cooperation among industry, academia, and government. Construction industry contributes to the improvement of global environment of the future generation in cooperation with other industries, academia and government.

\section{REFERENCES}

[1] Yamazaki, Y and Maeda, J 1998, The SMART system: an integrated application of automation and information technology in production process, Computers in Industry, Vol. 35, pp. 87-99

[2] Kodama, F 1992: Technology Fusion and The New R\&D, Harvard Business Review, pp.70-78

[3] Gann, D. M: Salter, A, J 2000: Innovation in project-based, service-enhanced firms: the construction of complex products and systems, Research Policy, 29, 955-972

[4] Nonaka, I 1990: A Theory of Organizational knowledge Creation. (in Japanese), Nihon Keizai Shinbun

[5] Construct IT Center of Excellence 1996, Construction Site Processes, Best Practice Benchmarking Report, Construct IT Center of Excellence, University of Salford

[6] Construct IT Center of Excellence 1997, A Health Check of Strategic Exploitation of IT, Construct IT Center of Excellence, University of Salford

[7] Construct IT Center of Excellence (1996), Construction Site Processes, Best Practice Benchmarking Report, Construct IT Center of Excellence, University of Salford

[8] Gan, D. M, et al 1996, Information Technology Decision Support in the Construction Industry, SPRU, University of Sussex

[9] Yamazaki, Y 1995, An Integrated construction Planning System using Object-oriented Product and Process Models, Construction Management and Economics, Vol.13, pp.417-426, E. \& F.N Spon [10] Yamazaki, Y 2000, Strategic Exploitation of Information Technology in Management of Largescale Construction Project CIT2000, Icelandic Building Research Institute, Vol.2, pp.1080-1089 [11] Yamazaki, Y 2003, Technology and Knowled ge Fusions toward Construction Innovation, Know ledge Construction, CIB+W55, W65, W107, pp.1080-1089 